\title{
Moral grandstanding and political polarization: A multi-study consideration
}

\author{
Joshua B. Grubbs ${ }^{\mathrm{a}, *}$, Brandon Warmke ${ }^{\mathrm{b}}$, Justin Tosi ${ }^{\mathrm{c}}$, A. Shanti James ${ }^{\mathrm{d}}$ \\ a Department of Psychology Bowling, Green State University, United States \\ ${ }^{\mathrm{b}}$ Department of Philosophy Bowling, Green State University, United States \\ ${ }^{\mathrm{c}}$ Department of Philosophy, Texas Tech University, United States \\ ${ }^{\mathrm{d}}$ Department of Psychology Bowling, Green State University, United States
}

\section{A R T I C L E I N F O}

\section{Article history:}

Received 22 May 2020

Revised 10 August 2020

Accepted 17 August 2020

Available online 24 August 2020

\section{Keywords:}

Narcissism

Status-seeking

Polarization

Virtue-signaling

Grandstanding

\begin{abstract}
A B S T R A C T
The present work posits that social motives, particularly status seeking in the form of moral grandstanding, are likely at least partially to blame for elevated levels of affective polarization and ideological extremism in the U.S. In Study 1, results from both undergraduates $(N=981$; Mean age $=19.4$; $S D=2.1 ; 69.7 \%$ women $)$ and a cross-section of U.S. adults matched to 2010 census norms $(N=1,063$; Mean age $=48.20, S D=16.38 ; 49.8 \%$ women ) indicated that prestige-motived grandstanding was consistently and robustly related to more extreme ideological views on a variety of issues. In Study 2, results from a weighted, nationally-representative cross-section of U.S. adults $(N=2,519$; Mean age $=47.5$, $S D=17.8 ; 51.4 \%$ women) found that prestige motivated grandstanding was reliably related to both ideological extremism and affective polarization.
\end{abstract}

(c) 2020 Elsevier Inc. All rights reserved.

\section{Introduction}

The American populace is sharply divided over political and moral issues (Dimock, Doherty, Kiley, \& Oates, 2014). Online outrage about political phenomena is common (Brady \& Crockett, 2019; Crockett, 2017), and there is considerable evidence that public discourse has become more ideologically polarized and less civil over the past several years (Doherty, Kiley, Tyson, \& Johnson, 2019). Several possible explanations of both increasingly polarized beliefs and a decline in civility have been posited, including economic trends, the behavior of political or party elites, media consumption, technological influences, and partisan sorting (Brady, Crockett, \& Van Bavel, 2019; McCarty, 2019). However, there is also growing evidence that individual differences may contribute to these trends. The present work examines one such individual difference-moral grandstanding motivation-that may be partially responsible for some of the divisions in contemporary American public discourse.

\footnotetext{
* Corresponding author at: Department of Psychology, Bowling Green State University, Bowling Green, $\mathrm{OH}, 43403$, United States.

E-mail address: GrubbsJ@BGSU.edu (J.B. Grubbs).
}

\subsection{Ideological extremism and affective polarization}

According to recent studies, politicians (Banda \& Cluverius, 2018), news media (Martin \& Yurukoglu, 2017), and average citizens (Johnston, 2018) are divided on a range of sociopolitical issues. Study of these divides has led to several recent empirical articles (for reviews, see: Iyengar, Lelkes, Levendusky, Malhotra, \& Westwood, 2019; Lelkes, 2016), books (e.g., McCarty, 2019), and even documentaries (e.g., "Divided States of America," 2017) on the rifts between political partisans in the U.S. Although there is broad consensus that some of these divides in the American populace are worsening (for a review, see: lyengar et al., 2019), the nature of political and partisan polarization is a controversial topic in political science (Abramowitz \& Saunders, 2008; Druckman \& Levendusky, 2019; Fiorina \& Abrams, 2008) and political psychology (Blatz \& Mercier, 2018; Westfall, Van Boven, Chambers, \& Judd, 2015). Some research has focused on divisions in the populace in terms of partisan identity (Abramowitz \& Saunders, 2008) and extreme endorsement of ideological views (Brandt, Reyna, Chambers, Crawford, \& Wetherell, 2014), whereas other work has focused on issue-based ideological divides (Fiorina \& Abrams, 2008 ) or emotional reactions to outgroup members (Iyengar, Sood, \& Lelkes, 2012). For the present work, we were interested in studying these divides in terms of ideological extremism and affective polarization. Given that these terms are often used differently across different disciplines, we define our use of each below. 


\subsubsection{Ideological extremism}

We use the term ideological extremism as it has been understood in prior psychological literature, namely, the extent to which people report extreme political or ideological views at either end of the political spectrum (Lammers, Koch, Conway, \& Brandt, 2017; van Prooijen \& Krouwel, 2019). That is, we conceptualized ideological extremism as the self-reported adoption of extreme political views in either direction. Relatedly, we will use the term ideological polarization to refer to the process by which an individual becomes more ideologically extreme. We will therefore think of polarization as the process that tends to result in ideological extremism. In this project, we were specifically interested in examining factors that predict ideological extremism (i.e., self-report of extreme political or ideological views), as such factors may also be related to the process of ideological polarization (i.e., the process by which one's reported views move to extremes).

For the present work, we considered ideological extremism as a key outcome variable in our analyses. However, we note ideological extremism itself often functions as an important predictor of symmetric effects in political and moral psychology (Brandt et al., 2014). Ideological extremists demonstrate overly simplistic evaluations of political phenomena (Fernbach, Rogers, Fox, \& Sloman, 2013; Lammers et al., 2017; van Prooijen, Krouwel, \& Emmer, 2018). Similarly, extremists are also likely to describe their beliefs as being objectively correct, regardless of the actual evidence for their beliefs (Toner, Leary, Asher, \& Jongman-Sereno, 2013). These same extremists are also more likely to reject outside influences on their decision making process (Brandt, Evans, \& Crawford, 2015). Finally, political extremism is likely associated with troubling outcomes, such as greater intolerance for nonlikeminded others, greater interpersonal conflict, greater incivility toward ideological others, and greater affective polarization (for reviews, see: Brandt et al., 2014; van Prooijen \& Krouwel, 2019).

\subsubsection{Affective polarization}

Voluminous bodies of work in social psychology demonstrate that people often show strong antipathy toward outgroup members and strong preference for ingroup members (for reviews, see: Hewstone, Rubin, \& Willis, 2002; Mackie, Maitner, \& Smith, 2016; Riek, Mania, \& Gaertner, 2006; Robbins \& Krueger, 2005). Similarly, groups often share emotions at the group level, particularly negative emotions in relation to outgroup members (Smith, Seger, \& Mackie, 2007). Researchers have found such antipathy across political lines as well. Consistent with previous research, we use the term affective polarization to refer to the phenomenon of demonstrating extreme positive affect toward members of one's preferred political party and extreme negative affect toward members of opposing political parties (Iyengar et al., 2019). That is, affective polarization is best understood as the gap between the extremity of one's affect toward the political outgroup and the extremity of one's affect toward the one's political ingroup. Importantly, affective polarization seems to function at least somewhat independently of ideological extremity. Even when people might be ideologically similar to members of another political party, affective reactions to those partisan others are often quite negative (Iyengar et al., 2012). People might experience extreme negative emotions toward political outgroup members independent of how ideologically different they are from said others (Iyengar et al., 2019).

There is clear evidence that affective polarization has increased over the past several decades (Iyengar et al., 2012; Mason, 2015). This has happened in multiple ways. First, more people have come to hold negative attitudes about those in the other party. For example, over a 50-year time span, the proportion of American adults who would object to their children marrying a member of the opposing political party rose from 4 to $5 \%$ in 1960 to $33-50 \%$ in
2010 (Iyengar et al., 2012). Second, individual antipathy toward ideological others has also apparently risen in recent years (Iyengar \& Westwood, 2015), with partisans themselves demonstrating stronger negative evaluations of opposing party members. The present work seeks to describe one factor that may be contributing to this rise in affective polarization: Moral Grandstanding.

\subsection{Status seeking and moral grandstanding}

Psychologists have long known that, when likeminded individuals discuss issues together as a group, they often leave such discussions with more extreme ideological positions than they entered with individually (Moscovici \& Zavalloni, 1969). This process of adopting more extreme views is known as group polarization (Mackie \& Cooper, 1984; Mackie, 1986). Similarly, groups may demonstrate collective emotions together, wherein extreme antipathy toward outgroup members is higher at the group level than at the individual level (Smith et al., 2007). Whereas past research, informed by social identity theory, has often speculated that conformity within the group is part of the reason for this process of polarization, the present work seeks to extend beyond these associations and examine how individual differences, such as a desire for status, might predict such divides.

As a hypersocial species, humans are characterized by a number of fundamental social motives that seem to influence behaviors and beliefs in a wide variety of domains (Neel, Kenrick, White, \& Neuberg, 2015). One such motive is status seeking (Anderson, Hildreth, \& Howland, 2015), which refers to the innate human drive to improve one's rank, station, and relative standing among others (Cheng, Tracy, Foulsham, Kingstone, \& Henrich, 2013). This drive for status may be seen in a variety of contexts including the workplace (Loch, Yaziji, \& Langen, 2001), social media environments (Nesi \& Prinstein, 2019), and even leisure pursuits (Walasek \& Brown, 2015). This tendency toward status seeking also seems to manifest in behavior in the context of public discourse (Grubbs, Warmke, Tosi, James, \& Campbell, 2019). Specifically, some people seem particularly prone to use moral talk (i.e., public discussions invoking moral rights, moral principles, moral ideals, and moral practices) as a means to attain higher status or standing in others' eyes. In both philosophical work (Tosi \& Warmke, 2016, 2020) and empirical inquiry (Grubbs et al., 2019), this use of moral talk to seek status is known as Moral Grandstanding (hereafter: MG).

First defined in the philosophical literature (Tosi \& Warmke, 2016), MG refers to the use of speech (broadly construed) about morality, politics, or other important topics to improve relative station or rank. People share their values, morals, or political beliefs in a variety of contexts for a variety of reasons. Sometimes these motivations are altruistic-they aim to help others (e.g., seeking to improve the quality of a conversation by providing an insight or new information; seeking to ameliorate suffering by defending an underdog). Motivations for engaging in public moral discourse may also be principled-some people simply aim to do what is right (e.g., seeking to stand up for what one takes as the right moral principles; seeking to do one's duty by telling the truth). However, some instances of moral talk are likely motivated by a strong desire to impress others, either by (1) demonstrating one's impressive moral qualities to one's in-group or by (2) attacking ideological rivals or opposites for allegedly inferior moral or political views. Prior psychological work has validated this notion of MG and found that the motivation to engage in MG is expressed in ways consistent with either a desire for prestige or a desire for dominance (Grubbs et al., 2019).

One way humans seek status is by trying to gain prestige, a kind of social status associated with being seen as knowledgeable, skilled, or impressive in some way (Cheng et al., 2013). Consistent 
with this conceptualization of status-seeking more broadly, one type of MG seems to be characterized by a desire for respect or admiration from others (e.g., "My beliefs should be inspiring to others"). This form of MG is associated with desires for prestige more generally and is well-predicted by narcissistic extraversion (Grubbs et al., 2019).

MG can also be motivated by a desire for status that results in dominating others. Here, grandstanders shame, hurt, or otherwise exploit potential rivals or ideological opponents (e.g., "When I share my beliefs, I do so in the hope that people different than me will feel ashamed of their beliefs"). Very much akin to more general status-striving via dominance (Cheng et al., 2013), this expression of MG seems to be motivated by a desire to assert one's rank or power over another person, or to elevate oneself by putting others down. This form of MG is particularly associated with more aggressive tendencies and is very well-predicted by narcissistic antagonism (Grubbs et al., 2019).

Importantly, preliminary empirical examinations of MG have shown that it is related to a number of potentially concerning behaviors and outcomes in public discourse (Grubbs et al., 2019). For example, MG is related to greater conflict with others over political and moral issues (both cross-sectionally and over time). MG is also related to greater engagement in antagonistic social media behaviors in discussions about politics (e.g., sharing messages or posts with the sole intent of shaming or embarrassing the original author of the post). Building on these findings, there may also be reason to suspect that MG relates to affective polarization and ideological extremism, as we explore below.

\subsection{Moral grandstanding and ideological extremism}

Philosophical work on MG predicts that grandstanders tend to stake out extreme moral and political positions to differentiate themselves from others in search of attention and praise (Tosi \& Warmke, 2016, 2020). The desire for status associated with MG likely leads people to express increasingly extreme political and moral opinions as a means of seeming more virtuous, respectable, or worthy of admiration than others in their group. MG leads people to "ramp up" their ideological positions (or at least their public presentations of them) to impress or appear superior to others. As individuals seek status, they may take progressively more extreme positions in their respective groups as a means of presenting themselves as moral paragons. In short, the motivation to engage in MG is likely associated with adopting more extreme ideological positions.

For example, consider a discussion between likeminded individuals, each of whom thinks of herself as caring deeply for the poor. If someone says that justice demands a $\$ 15$ per hour minimum wage, another can simply respond that it would be even more just to institute a $\$ 20$ per hour minimum wage. In a grandstanding-rich environment, the others in the group now must either accept that this person seems to care more for the poor or adjust their own stated views to keep up. If enough others in the group accept the ramped-up claim, those with doubts or concerns risk being left behind or called out as naysayers. Consistent with previously referenced literature on group polarization and social conformity (e.g., Mackie, 1986), many people find it more palatable to subtly calibrate their views according to their in-group's platform than to risk apostate status. In short, MG might lead to extremism about any given issue.

A similar dynamic can play out among a likeminded group in response to the views of an out-group. Ramping up can occur when group members engage in a competition to see who despises the out-group the most, with the winner holding the strongest contrary view, and thus, the moral high ground. Meanwhile, the inverse of this competition could happen among the other group as well. This ramping up effect may happen not only with respect to one's ideological views, but also with one's affective reactions to the other side, such that individuals in each group coming to hate the other side more. MG may therefore not only cause ideological extremism but also affective polarization.

As public discourse comes to resemble a moral arms race, both affective polarization and ideological polarization (i.e., increasing amounts of ideological extremism) are predictable consequences. As such, we might expect to find that MG is linked to more ideological extremism and affective polarization, particularly among those who are seeking prestige or respect from likeminded others.

Consistent with these philosophical insights, preliminary evidence suggests that MG is associated with more extreme political views. MG motivations-particularly in the domain of prestigeare associated with ideological extremism, demonstrating a curvilinear relationship with single-item ratings of political ideology (Grubbs et al., 2019). In these preliminary samples of college students and weighted nationally-representative cross-sections in the U.S., individuals who identified as being more extreme in their political views (i.e., more to the "left" or the "right" on a sliding scale rating of political ideology) also reported a greater desire to use moral talk as a means of appearing respectable, admirable, or inspirational to others. However, to date, no work has systematically examined the nature of these links beyond simple correlational analyses or determined whether these links persist in measurement environments more rigorous than single-item ideology scales. The present work seeks to address these areas of deficit.

\subsection{The present work}

Building on the literature reviewed above, the present work examines the relationships between MG and both ideological extremism and affective polarization in the general public, specifically testing whether MG predicts greater levels of both. In Study 1 , we focused solely on ideological extremism using novel measures of self-identified political orientation in general and in relation to specific issue/positions. That is, we examined ideological extremism as the gap between participants self-report of themselves being conservative/traditional or liberal/progressive in general and in relation to specific policy domains. In Study 2, we examined both general ideological extremism using traditional measures of ideological extremity and affective polarization using widely accepted measures of gaps in partisan affect.

Given that prestige-motivated aspects of MG are closely related to a desire to appear morally impressive to likeminded others, it seems likely that individuals who report greater prestigemotivated MG would also report more extreme views within their own partisan groups. Similar to more seminal works in social psychology around optimal distinctiveness theory (Brewer, 2011; Leonardelli, Pickett, \& Brewer, 2010), the basic thought is that people who are strongly inclined to use moral discourse to impress others will also be inclined to adopt more extreme ideological positions because these views help them "stand out" among the crowd. Though such views are seen as extreme by outsiders, they may be seen as more respectable or admirable within their group. Essentially, it seems that these individuals will take extreme positions in order to garner status and esteem among ideological peers. Therefore, we expected to find that prestige-motivated MG would be associated with greater levels of ideological extremism.

In contrast with the desire for respect and esteem associated with prestige seeking, dominance-motivated aspects of MG convey a desire to assert one's rank or power over another by causing others shame or feelings of inferiority. These tendencies are inherently related to antipathy toward ideological opponents. As such, we might expect to find that dominance-motivated aspects of MG are related to more extreme affective reactions toward 
outgroup members. The idea is that people who are strongly inclined to use moral discourse to dominate and humiliate others will be also more inclined to feel and express extreme emotional responses, since these emotional responses can effectively intimidate and instill fear.

Although there is very little prior work suggesting that narcissism might be related to ideological extremism, some recent findings have demonstrated that narcissistic antagonism and narcissistic extraversion are very strongly related to MG motivations and that narcissistic antagonism often predicts conflict with others over political and moral issues (Grubbs et al., 2019). Given these associations, we included narcissistic antagonism and narcissistic extraversion as covariates in our analyses, allowing us to address the possibility that links between MG and polarization might be related to the status-oriented personality traits underlying $\mathrm{MG}$ rather than $\mathrm{MG}$ alone.

Finally, we note that the present work is a secondary analysis of previously collected data that were partially described in a prior publication (Grubbs et al., 2019). Specifically, this earlier work reported associations between basic personality traits and MG, with a focus on validating the construct and measurement of MG. However, several of the datasets on which the prior work reported also included measures of polarization and ideological extremism that were not included in the earlier publication. Although our analytic plan was theoretically driven by the above ideas, this work was not pre-registered, and we do not believe that our results should be interpreted as confirmation of a prespecified hypothesis.

More details regarding this entire project, including analytic code and data, are available via the Open Science Framework at https://osf.io/3mpx2/.

\section{Study 1}

To initially test the above ideas and examine the links between MG and polarization, we collected two samples, as detailed below.

\subsection{Participants}

Participants for Sample 1 were undergraduates at a large, public university in the Midwest. Participants $\left(N=981 ; M_{\text {age }}=19.4\right.$; $S D=2.1 ; 69.7 \%$ women) were recruited from undergraduate psychology classes throughout the university over the course of four semesters (Fall 2017, Spring, 2018, Fall 2018, and Spring 2019). Sample size was determined by maximizing participation over four semesters, rather than by a priori power analyses. Participants were able to select the racial or ethnic category that they felt best applied to themselves (including multiple categories); as such, totals reported below may exceed $100 \%$. Participants primarily identified as White (84\%), followed by African-American/Black (12.9\%), Latino/a/Hispanic (3.6\%), Asian/South-Asian/Pacific-Islan der $(2.1 \%)$, American Indian/Native-American (1.0\%), and other (1.5\%). Political affiliations reported by participants were as follows: Democrat (31\%), Republican (26.4\%), no party affiliation (27.1\%); Libertarian (5.0\%), Green (0.8\%), Independent (8.6\%), and other (1.1\%).

Participants for Sample 2 were internet-using adults in the United States recruited by the Turkprime data-acquisition platform (now known as Cloud Research; Litman, Robinson, \& Abberbock, 2017). Participants $\left(N=1063 ; M_{\text {age }}=48.20, S D=16.38 ; 49.8 \%\right.$ women) were recruited in the Summer of 2018 based on U.S. demographic norms as of the 2010 census for Race, Ethnicity, Income, Census Region, Age, and Gender. Sample size was determined by funding limits, rather than by a priori power analyses. More simply, budgetary constraints led us to recruit a target of
1000 participants. Although participants were recruited based on U.S. nationally representative norms, participants were able to select the racial or ethnic category that they felt best applied to themselves (including multiple categories); as such, totals reported below may exceed $100 \%$. Participants were primarily White (73.8\%), followed by African-American/Black (11.4\%), AsianPacific Islander (8.4\%), Latino/a/Hispanic (7.1\%), American-Indian /Native-American (3.2\%), and other (1.6\%). Participants primarily identified as Democrat (35.7\%), followed by Republican (28.9\%), Independent (21.4\%), no party affiliation (11.2\%), Libertarian (1.8\%), and Other (1.1\%).

\subsection{Measures}

\subsubsection{Moral grandstanding}

We included the Moral Grandstanding Motivations Scale (Grubbs et al., 2019). This 10-item measure requires participants to respond on a scale of 1 (Strongly Disagree) to 7 (Strongly Agree) to items on two subscales. The first, six-item subscale assesses the extent to which participants are motivated to use moral talk to seek prestige or respect (e.g., "My beliefs should be inspiring to others" and "I hope that my beliefs cause other people to want to share those beliefs"). The resulting subscale score is titled Prestige Strivings. The second, four-item subscale assesses the extent to which participants are motivated to use moral talk to dominate or shame others (e.g., "When I share my beliefs, I do so to show people who disagree with me that I am better than them"). The resulting subscale score is titled Dominance Strivings.

\subsubsection{Ideological extremism}

For these samples, we assessed ideological extremism via a novel measure of absolute ideological gap. That is, we measured the absolute magnitude of the gap between participants' selfreported endorsement of Conservative/Traditional ideology and Liberal/Progressive ideology, so that a greater gap value represented more polarized views of various political domains.

Political views were assessed in five domains: overall political views (prompt: "To what extent do the following items describe your political views?"), fiscal views (prompt: "To what extent are your fiscal (money, budget, tax, and finance) views politically:"), social views (prompt: "To what extent are your social (welfare, entitlements, social-security, and education) views politically:”), moral views (prompt: "To what extent are your moral (marriage, sexuality, abortion/reproductive-rights) views politically:"), and foreign-policy views (prompt: "To what extent are your foreign policy views (military and war; U.S. involvement overseas; U.S. involvement in nation building) politically:").

For each of the above categories, we asked participants to rate the extent to which their political views were "Conservative," "Liberal," "Progressive," or "Traditional" on a seven-point scale of 0 (Not at all) to 6 (Extremely). That is, we asked participants to respond to all four descriptors ("Conservative," "Liberal," "Progressive," and "Traditional”) for all five domains. ${ }^{1}$

We calculated our index of ideological extremism using the following formula:

$\sqrt{(\text { Mean }(\text { Conservative }+ \text { Traditional })-\text { Mean }(\text { Liberal }+ \text { Progressive }))^{2}}$

\footnotetext{
1 Given the novelty of this approach, we tested the general validity of responses by examining how participants in each sample differed on raw ratings in each domain Specifically, we compared self-identified Democrats and self-identified Republicans within each sample on each of the items described above. For all domains, selfidentified Democrats scored substantially higher than self-identified Republicans for ratings of Liberal and Progressive and substantially lower than self-identified Republicans for ratings of Conservative and Traditional. These analyses are available via the OSF page for this project at https://osf.io/jgecm/ and https://osf.io/85mec/.
} 
Within each domain, we averaged participant ratings of Conservative and Traditional responses options, then subtracted from this value the average participant ratings for Progressive and Liberal response options. This process created an index with a possible range of -6 to +6 , wherein a more liberal ideological gap was represented by lower values and a more conservative ideological gap was represented by more positive values. We then squared these indices and took the square root of the resulting values to create a series of indicators of unidirectional ideological extremism so that more extreme values (i.e., values closer to $|6|$ ) were indicative of higher ideological gap and less extreme values (i.e., values closer to zero) were indicative of lower ideological gap. In sum, this created an index of absolute extremism in each domain, regardless of direction.

\subsubsection{Narcissism}

Given the robust associations between narcissistic traits and MG in prior works, we included the Five Factor Narcissism Inventory Short Form in our analyses as a covariate (Sherman et al., 2015). The FFNI-SF measures numerous domains of narcissistic personality along several facets. We focused on two composite indices that have previously shown robust associations with MG: Narcissistic Antagonism (exploitative, aggressive, and entitled aspects of narcissism that are strongly associated with MG: Dominance Strivings) and Narcissistic Extraversion (grandiose and self-important aspects of narcissism that are strongly associated with MG: Prestige Strivings).

\subsection{Analytic plan}

In both samples, we computed full descriptive statistics, analysis of internal consistency (Cronbach's $\alpha$ and McDonald's $\omega$ ), and simple product-moment correlations between all key variables. These variables are all reported in Table 1.

Subsequent to these analyses, we conducted a Structural Equation Model (SEM) in each sample using the lavaan package (Rosseel, 2012) for R Statistical Software (R Core Team, 2018). All analyses were conducted using maximum likelihood estimation with robust (Huber-White) standard errors and a scaled test statistic. In these analyses, for each sample, we defined the latent variables MG: Prestige and MG: Dominance by the items of the corresponding subscales of the MGMS. We also defined the latent variable Ideological extremism by the five absolute indices of partisan ideological gap (Overall, Fiscal, Social, Moral, and Foreign Policy) described above. In the full SEM, MG: Prestige and MG: Dominance were regressed on observed exogenous variables FFNI: Antagonism and FFNI: Extraversion. In turn, Ideological extremism was regressed on MG: Prestige, MG: Dominance, FFNI: Antagonism, and FFNI: Extraversion. MG: Prestige and MG: Dominance were allowed to covary. Similarly, FFNI: Antagonism and FFNI: Extraversion were allowed to covary. This model is summarized in Fig. 1.

\section{Study 1 Results}

In both samples, Pearson correlations revealed small to moderate associations between MG motivations and ideological extremism across all indicators (See Tables 1 and 2). In Sample 1, for MG: Prestige these associations were most often positive and moderate in size (i.e., $r>0.2$; Funder \& Ozer, 2019). In contrast, associations for MG Dominance and ideological gaps were consistently small and negative. In Sample 2, a similar pattern was observed, with small positive associations (i.e., $r<0.1$; Funder \& Ozer, 2019) being observed between MG Prestige and polarization measures, and small negative associations between MG Dominance and polarization measures. In both samples, narcissistic antagonism was nega- tively associated with polarization measures. Finally, in both samples, the intercorrelations of the various polarization indices were large and positive (i.e., $r=0.653-0.821$ ).

With regard to our planned SEM analyses: Our specified models demonstrated good fit in both samples (Robust Fit Indices; Sample $1: \chi^{2}[111]=297.99, \mathrm{CFI}=0.975$, TLI $=0.969$, RMSEA $=0.041$, SRMR $=0.044$; Sample 2: $\chi^{2}[111]=311.78$, CFI $=0.977$, $\mathrm{TLI}=971, \mathrm{RMSEA}=0.046, \mathrm{SRMR}=0.035){ }^{2}$ In both samples, FFNI Antagonism was unrelated to MG: Prestige. Similarly, in both samples, FFNI Antagonism demonstrated strong positive associations with MG: Dominance, and FFNI Extraversion demonstrated strong positive associations with MG: Prestige. In turn, MG: Prestige demonstrated robust associations with Ideological extremism, whereas the relationship between MG: Dominance and Ideological extremism did not reach statistical significance. Moreover, in both samples, the total variance accounted for in Ideological extremism was similar (Sample $1, R^{2}=0.110$; Sample $2, R^{2}=0.112$ ).

We also considered an alternative interpretation of our data in which extremism may be understood as predicting MG. That is, we tested alternatives to our structural model (where MG predicts extremism) rather than assuming that ours is the most plausible interpretation of our data. To accomplish this, in both samples, we compared the above described model to an alternative model in which MG: Dominance and MG: Prestige were regressed on Ideological extremism (i.e., where Ideological extremism predicted MG: Dominance and MG: Prestige) rather than the converse. However, such a model demonstrated a noticeably inferior fit in both samples (Sample 1, alternative model fit: $\chi^{2}[113]=333.87$, $\mathrm{CFI}=0.971$, TLI $=0.965$, RMSEA $=0.048$, SRMR $=0.059 ; \chi_{\text {dif }}^{2}$ $[2]=40.316, p<.001$; Sample 2, alternative model fit: $\chi^{2}[113]=343.41$, CFI $=0.973$, TLI $=0.968$, RMSEA $=0.048$, SRMR $\left.=0.060 ; \chi_{\text {dif }}^{2}[2]=35.267, p<.001\right)$. That is, our theoretically expected models (See Fig. 1), are more consistent with the data obtained than an alternative model wherein polarization may be seen as predicting grandstanding.

\subsection{Study 1 Discussion}

Results of our first study demonstrated that, in two large samples, greater motivation to engage in moral grandstanding for prestige-based reasons was consistently related to greater ideological extremism. This finding persisted even when narcissistic traits were held constant statistically, suggesting that prestige motivated MG is uniquely related to extremism, beyond its links to narcissism. Moreover, consistent with our predictions, our specified model (where MG predicted extremism) demonstrated better fit than an alternative model where extremism predicted MG. Of note, we found consistently negative links between dominance motivated MG and extremism when narcissistic antagonism was not included, and insignificant links between dominance and extremism when narcissism was included. These findings were contrary to our initial hypotheses and suggest that, to the extent MG: Dominance is related to ideological extremism, it is likely a function of the close relationship between narcissistic antagonism and dominance.

Despite our findings regarding prestige motivated MG, these results demonstrated only preliminary links between MG and partisan divides, for many reasons. For example, these results did

\footnotetext{
${ }^{2}$ We also conducted these analyses without a latent ideological extremism variable (i.e., with just observed gap indices) and another model without narcissism as a covariate. These results are available via the Open Science Framework at https://osf. io/68wy9/ as Supplemental Fig. 1 and Supplemental Table 4. Of note, patterns of association for MG: Prestige remained highly similar across all alternate analyses, though MG: Dominance demonstrated significant negative associations with ideological extremism in models where narcissism was not included.
} 
Table 1

Study 1, Sample 1: Descriptive Statistics, Internal Consistency Coefficients, and Correlations.

\begin{tabular}{|c|c|c|c|c|c|c|c|c|c|c|c|}
\hline & & & $\begin{array}{l}\text { MG } \\
\text { Prestige }\end{array}$ & $\begin{array}{l}\text { MG } \\
\text { Dominance }\end{array}$ & $\begin{array}{l}\text { Narc. } \\
\text { Antagonism }\end{array}$ & $\begin{array}{l}\text { Narc. } \\
\text { Extraversion }\end{array}$ & $\begin{array}{l}\text { Fiscal } \\
\text { Gap }\end{array}$ & $\begin{array}{l}\text { Social } \\
\text { Gap }\end{array}$ & $\begin{array}{l}\text { Moral } \\
\text { Gap }\end{array}$ & $\begin{array}{l}\text { Foreign } \\
\text { Gap }\end{array}$ & $\begin{array}{l}\text { Overall } \\
\text { Gap }\end{array}$ \\
\hline \multirow[t]{12}{*}{$\begin{array}{l}\text { Sample } 1 \\
\qquad(N=981)\end{array}$} & MG Prestige & $\begin{array}{l}M=4.20 \\
S D=1.11 \\
\alpha=0.815 \\
\omega=0.818\end{array}$ & & & & & & & & & \\
\hline & MG & $M=2.24$ & $0.114^{* *}$ & & & & & & & & \\
\hline & Dominance & $\begin{array}{l}S D=1.28 \\
\alpha=0.876 \\
\omega=0.880\end{array}$ & & & & & & & & & \\
\hline & Narc. & $M=2.33$ & 0.054 & $0.510^{* *}$ & & & & & & & \\
\hline & Antagonism & $\begin{array}{l}S D=0.59 \\
\alpha=0.835 \\
\omega=0.845\end{array}$ & & & & & & & & & \\
\hline & Narc. & $M=3.33$ & $0.276^{* * *}$ & $0.071^{*}$ & $0.323^{* *}$ & & & & & & \\
\hline & Extraversion & $\begin{array}{l}S D=0.62 \\
\alpha=0.640 \\
\omega=0.657\end{array}$ & & & & & & & & & \\
\hline & Fiscal Gap & $\begin{array}{l}M=1.65 \\
S D=1.70\end{array}$ & $0.215^{* *}$ & $-0.076^{*}$ & $-0.120^{* *}$ & $0.071^{*}$ & & & & & \\
\hline & Social Gap & $\begin{array}{l}M=1.92 \\
S D=1.92\end{array}$ & $0.216^{* *}$ & $-0.111^{* *}$ & $-0.172^{* *}$ & 0.057 & $0.759^{* *}$ & & & & \\
\hline & Moral Gap & $\begin{array}{l}M=2.39 \\
S D=2.16\end{array}$ & $0.200^{* *}$ & $-0.141^{* *}$ & $-0.175^{* *}$ & 0.036 & $0.653^{* *}$ & $0.752^{* * *}$ & & & \\
\hline & Foreign Gap & $\begin{array}{l}M=1.75 \\
S D=1.89\end{array}$ & $0.196^{* *}$ & $-0.078^{*}$ & $-0.137^{* *}$ & 0.027 & $0.762^{* *}$ & $0.762^{* *}$ & $0.685^{* *}$ & & \\
\hline & Overall Gap & $\begin{array}{l}M=1.89 \\
S D=1.77\end{array}$ & $0.209^{* *}$ & $-0.084^{* *}$ & $-0.172^{* *}$ & 0.010 & $0.774^{* *}$ & $0.821^{* * *}$ & $0.775^{* *}$ & $0.769^{* *}$ & \\
\hline
\end{tabular}

$\alpha=$ Cronbach's Alpha; $\omega=$ McDonald's Omega.

MG = Moral Grandstanding; Narc $=$ Narcissism.

${ }^{* *}$ Correlation is significant at the 0.01 level (2-tailed).

* Correlation is significant at the 0.05 level (2-tailed).

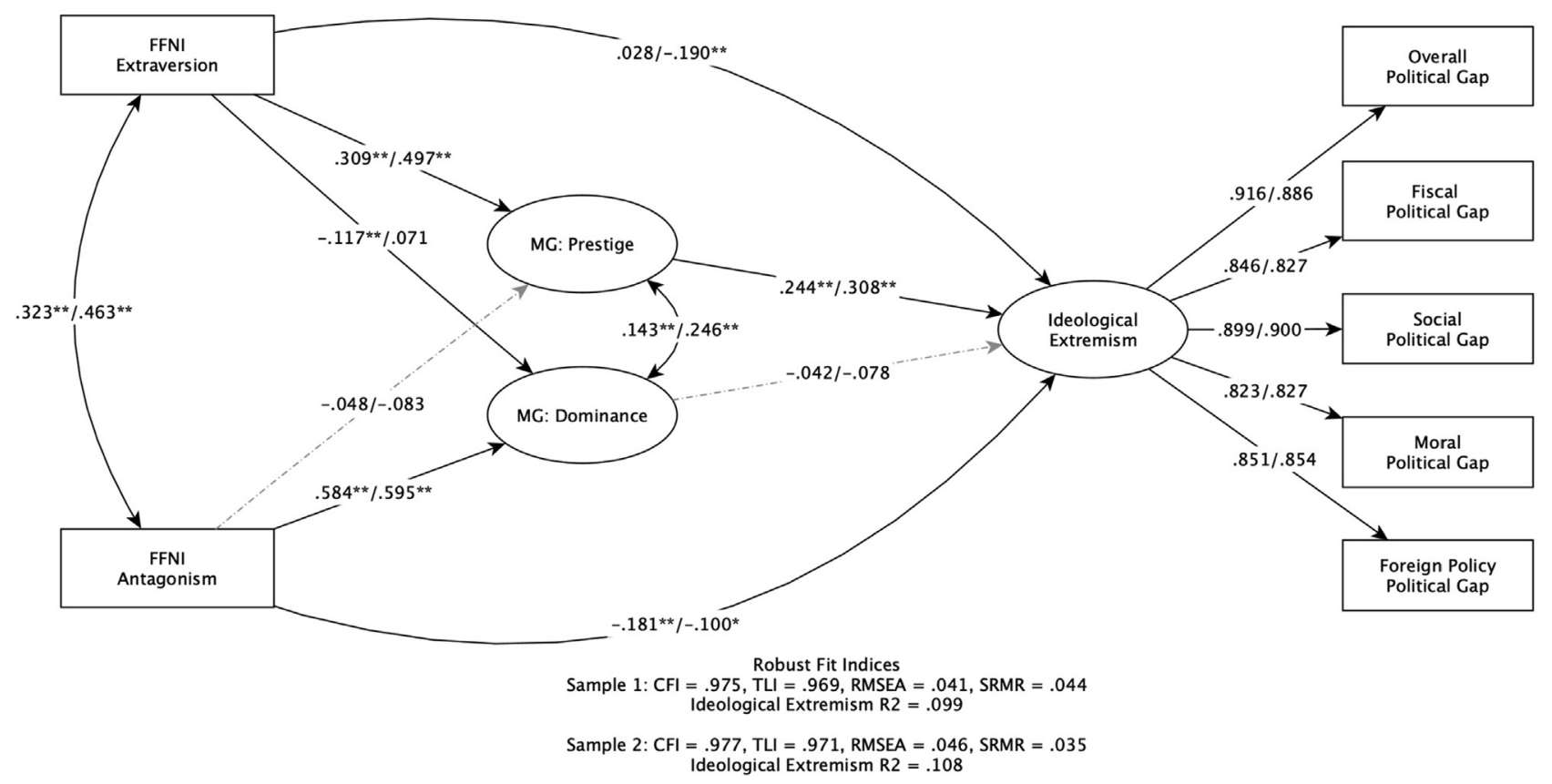

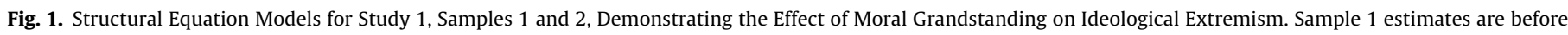

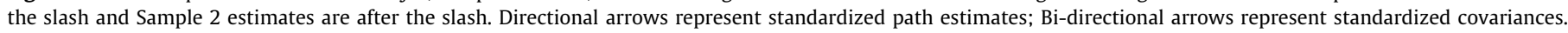

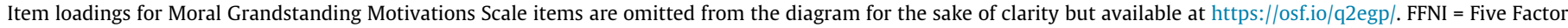

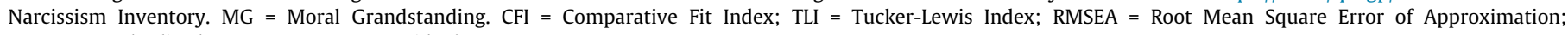
SRMR = Standardized Root Mean Square Residual.

not address affective polarization, were based on novel and idiosyncratic measures of ideological extremism, and did not control for general political interest. Given that political polarization implies some measure of political and news interest, it is possible that a series of questions related to moral and political beliefs may be indirectly measuring political interest rather than status seeking via contributions to moral and political discourse. More simply, it may be that links between MG and political polarization are better 
Table 2

Study 1, Sample 2: Descriptive Statistics, Internal Consistency Coefficients, and Correlations.

\begin{tabular}{|c|c|c|c|c|c|c|c|c|c|c|}
\hline & & & $\begin{array}{l}\text { MG } \\
\text { Prestige }\end{array}$ & $\begin{array}{l}\text { MG } \\
\text { Dominance }\end{array}$ & $\begin{array}{l}\text { Narc. } \\
\text { Antagonism }\end{array}$ & $\begin{array}{l}\text { Narc. } \\
\text { Extraversion }\end{array}$ & $\begin{array}{l}\text { Fiscal } \\
\text { Gap }\end{array}$ & $\begin{array}{l}\text { Social } \\
\text { Gap }\end{array}$ & $\begin{array}{l}\text { Moral } \\
\text { Gap }\end{array}$ & $\begin{array}{l}\text { Foreign } \\
\text { Gap }\end{array}$ \\
\hline \multirow[t]{5}{*}{ Sample $2(N=1063)$} & MG & Prestige & $\begin{array}{l}M=4.30 \\
S D=1.25 \\
\alpha=0.843 \\
\omega=0.844\end{array}$ & & & & & & & \\
\hline & MG & & Dominance & $\begin{array}{l}M=2.41 \\
S D=1.44 \\
\alpha=0.912 \\
\omega=0.912\end{array}$ & $0.263^{* *}$ & & & & & \\
\hline & & Narc. Anta & onism & $\begin{array}{l}M=2.24 \\
S D=0.63 \\
\alpha=0.852 \\
\omega=0.858\end{array}$ & $0.142^{* *}$ & $0.599^{* *}$ & & & & \\
\hline & & Narc. Extra & version & $\begin{array}{l}M=2.96 \\
S D=0.72 \\
\alpha=0.733 \\
\omega=0.739\end{array}$ & $0.389^{* *}$ & $0.333^{* *}$ & $0.463^{* *}$ & & & \\
\hline & & Fiscal Gap & & $\begin{array}{l}M=2.00 \\
S D=1.84\end{array}$ & $0.105^{* *}$ & $-0.070^{*}$ & $-0.126^{* *}$ & $-0.095^{* *}$ & & \\
\hline Social Gap & & $\begin{array}{l}M=2.19 \\
S D=1.92\end{array}$ & $0.129^{* *}$ & $-0.113^{* * *}$ & $-0.168^{* * *}$ & $-0.112^{* * *}$ & $0.725^{* * *}$ & & & \\
\hline Moral Gap & & $\begin{array}{l}M=2.54 \\
S D=2.07\end{array}$ & $0.093^{* *}$ & $-0.179^{* *}$ & $-0.206^{* *}$ & $-0.132^{* *}$ & $0.653^{* *}$ & 0.772 & & \\
\hline Foreign Gap & & $\begin{array}{l}M=1.92 \\
S D=1.90\end{array}$ & $0.129^{* *}$ & $-0.073^{*}$ & $-0.141^{* *}$ & $-0.081^{* *}$ & $0.757^{* *}$ & $0.760^{* *}$ & $0.696^{* *}$ & \\
\hline Overall Gap & & $\begin{array}{l}\mathrm{M}=2.27 \\
\mathrm{SD}=1.85\end{array}$ & $0.131^{* *}$ & $-0.073^{*}$ & $-0.180^{* *}$ & $-0.114^{* *}$ & $0.743^{* *}$ & $0.803^{* *}$ & $0.730^{* *}$ & $0.747^{* * *}$ \\
\hline
\end{tabular}

$\alpha=$ Cronbach's Alpha; $\omega=$ McDonald's Omega.

MG = Moral Grandstanding; Narc = Narcissism.

** Correlation is significant at the 0.01 level (2-tailed).

Correlation is significant at the 0.05 level (2-tailed).

explained by how politically engaged a person is, rather than a true relationship between engaging in MG and adopting more extreme views. We sought to address these possible limitations in Study 2.

\section{Study 2}

To extend the findings from Study 1 to a weighted, nationally representative sample, to account for general political interest, to measure ideological extremism using a more traditional measure, and to extend our models to affective polarization as well, we collected a cross-sectional sample of the U.S. population, as described below.

\subsection{Participants}

Participants were adults in the U.S. $\left(\mathrm{N}=2519 ; M_{a g e}=47.5\right.$, $S D=17.8 ; 51.4 \%$ women) recruited via YouGov polling and matched to nationally representative (2016 American Community Survey) norms for age, gender, race, education, and U.S. Census Region. Participants identified primarily as $38.7 \%$ Democrat, 27.2\% Republican, 25.4\% Independent, 3.6\% other, and 5.1\% not sure. Race was reported as follows: $64.1 \%$ White, $12.0 \%$ Black, 15.7\% Hispanic, 3.3\% Asian, 0.9\% Native American, 2.5\% Mixed, $1.5 \%$ other, $0.2 \%$ Middle Eastern. Responses were weighted using YouGov's proprietary weighting formulae (Rivers, 2016).

\subsection{Measures}

We measured moral grandstanding motivations and narcissistic extraversion/antagonism using the same measures as Study 1.
However, we assessed ideological extremism differently than in Study 1 and also assessed affective polarization as described below.

\subsection{Ideological extremism}

We asked participants to rate their political beliefs from "left" to "right" on a sliding scale with an anchor of -100 (liberal or progressive) on the left and +100 (conservative or traditional) on the right. We then folded this measure, keeping the absolute value of one's self-rating, with more extreme values signifying polarization, regardless of the direction of such polarization. This resulting index was termed Ideological Extremism: Left-Right Spectrum.

We also included panel data provided by YouGov on the strength of political ideology. This data was collected prior to the administration of our study and is a standard part of the political information maintained by YouGov as a part of all panel-based research they facilitate. For this item, participants responded to the item, "In general, how would you describe your own political viewpoint?" on a scale of 1 (very liberal) to 5 (very conservative). For this index of polarization, consistent with prior research (Brandt et al., 2015; Garrett \& Bankert, 2018; Wegener, Downing, Krosnick, \& Petty, 1995), we folded this scale at the midpoint, with the highest score (2) representing very liberal or very conservative and the lowest score $(0)$ indicating moderate ideology. In keeping with prior literature on this topic, the resulting index was titled: Ideological Extremism: Panel Ideology.

\subsection{Affective polarization}

We assessed affective polarization via two methods. First, we used a gap index based on a feeling thermometer wherein partici- 
pants were asked to rate their feelings toward individuals with specific political affiliations on a scale of 0 (very cold or completely negative) to 100 (very warm or completely positive). Participants were asked to rate their feelings toward Democrats and Republicans. Consistent with recent works examining gap in partisan affect (Garrett \& Bankert, 2018; Garrett, Long, \& Jeong, 2019; Iyengar \& Westwood, 2015), we looked at the gap in feelings toward each party by subtracting feelings toward Republicans from feelings toward Democrats. This created a variable on a scale of -100 to +100 . We then squared these results and then took the square root of these squares so that all answers were on a scale of $0-100$. By doing so, we created a linear absolute-value index of polarization wherein more extreme affective polarization was represented by higher values and lower levels of affective polarization were represented by lower values. The resulting variable was called Affective Polarization: Feeling Thermometer Gap.

Consistent with prior work in political science (i.e., Iyengar et al., 2012), we also asked participants how they would feel about a child or other close loved one married a member of certain political parties (Republicans and Democrats). Participants rated their reactions to the following prompt: "How would you feel if your child married someone who identified as: (note: if you do not have children, you can imagine how you feel if a close friend or family member married someone who identified as the following descriptors)" on a scale of 0 (completely negative) to 100 (completely positive). For this variable, we followed a similar technique as we did above. We created an affective gap index by subtracting feelings toward Republicans from feelings toward Democrats, squaring this resulting gap index, then taking the square root of the squared value to create a single, linear measure of polarization. The resulting variable was called Affective Polarization: Child's Marriage Gap.

\subsection{Political interest}

In addition to the above measures of polarization, we also analyzed panel data from YouGov regarding participants' interest in politics using a standard item from the American National Election Study (ANES). YouGov maintains participant responses to the standard prompt: "Some people seem to follow what's going on in government and public affairs most of the time, whether there's an election going on or not. Others aren't that interested. Would you say you follow what's going on in government and public affairs..." Responses were recorded on a scale of 1 (Most of the time) to 4 (Hardly at all). For ease of interpretation, we reversed the scoring of this item so that greater values indicated more interest in politics. This resulting score was termed Political Interest.

\subsection{Analytic plan}

All analyses were weighted using population weights provided by YouGov. Analyses for Study 2 were very similar to Study 1 . We conducted Pearson product-moment correlations between all variables. We followed these correlations with an SEM analyses in lavaan similar to those reported in Study 1. Specifically, we defined the latent variables MG Prestige and MG Dominance by the respective subscale items of the MGMS. These variables were again regressed on observed variables FFNI Antagonism and FFNI Extraversion, as well as the observed variable Political Interest. In turn, Affective Polarization: Feeling Thermometer Gap, Affective Polarization: Child's Marriage Gap, Ideological extremism: LeftRight Spectrum, and Ideological Extremism: Panel Ideology were all regressed on the aforementioned variables described above. This model is summarized in Fig. 2.

\section{Results}

Pearson correlations revealed highly similar results to those found in Study 1 (See Table 3). Specifically, we consistently found positive associations between computed indices of partisan polarization (both ideological and affective) and MG motivations, particularly prestige motivations, though these associations were typically small to moderate in size $(r=0.1-0.2$; Funder \& Ozer, 2019). See Table 2.

In our subsequent SEM analysis, we found similar patterns to those observed in Study 1. The fit of our model was good (Robust Fit Indices: $\mathrm{CFI}=0.977, \mathrm{TLI}=0.966$, RMSEA $=0.043, \mathrm{SRMR}=0.038$ ). These results are summarized in Fig. 2. Specifically, consistent with Study 1, we saw strong positive associations between FFNI: Antagonism and MG: Dominance and between FFNI: Extraversion: and MG: Prestige. Additionally, analyses demonstrated positive associations between general political interest and both MG: Dominance and MG: Prestige.

With regard to our outcome variables, results were generally consistent with Study 1 . General interest in politics was positively associated with all forms of polarization, as was MG: Prestige. MG: Dominance was only positively associated with Ideological Strength and affective polarization in the form of feelings about children's marriages. Both FFNI Antagonism and FFNI Extraversion demonstrated sporadic relationships with polarization, either being negatively related to polarization or not significantly related at all. Variance accounted for in each outcome variable by our model ranged from $R^{2}=0.092$ for ideological identification to $R^{2}=0.240$ for affective polarization as indicated by feeling thermometer responses.

Consistent with Study 1, we also tested alternative SEMs and compared them to our preferred model reported above. The first alternative model we tested followed a similar pattern to alternative models in Study 1, wherein MG variables were treated as outcomes predicted by all other variables. In this alternative model, MG: Prestige and MG: Dominance were regressed on observed polarization and extremism indices. This model demonstrated much worse fit than the above reported model (Robust Fit Indices: $\mathrm{CFI}=0.768, \mathrm{TLI}=0.671$, RMSEA $=0.105$, SRMR $=0.096$; $\left.\chi_{\text {dif }}^{2}[6]=2089.3, p<.001\right)$. Additionally, we specified another alternative model wherein we defined a latent variable, General Polarization using all observed polarization indices as indicators. This model also demonstrated worse fit than the above described model wherein each observed polarization index was treated as an independent outcome (Robust Fit Indices: $\mathrm{CFI}=0.953$, TLI $=0.941$, RMSEA $=0.057$, SRMR $\left.=0.045 ; \chi_{\text {dif }}^{2}[17]=318.6, p<.001\right)$. Finally, we specified an alternative model where Ideological Extremism: Panel Ideology was included as an exogenous covariate in the model, predicting both MG: Prestige and MG: Dominance, as well as the remaining three measures (Ideological Extremism: Left/ Right Spectrum; Affective Polarization: Feeling Thermometer; and Affective Polarization: Child's Marriage Gap). In testing this model, we found adequate fit ( CFI $=0.975$, TLI $=0.963$, RMSEA $=0.045$, SRMR $=0.040$ ), but again found that our original model demonstrated better fit by a significant margin $\left(\chi_{\text {dif }}^{2}[2]=15.383, p<.001\right)$.

\subsection{General discussion}

Past work in philosophy has argued that MG has a polarizing effect in public discourse. We evaluated this possibility in three samples, examining both ideological extremism and affective polarization. Below we summarize our findings and discuss the implications of the present work. 


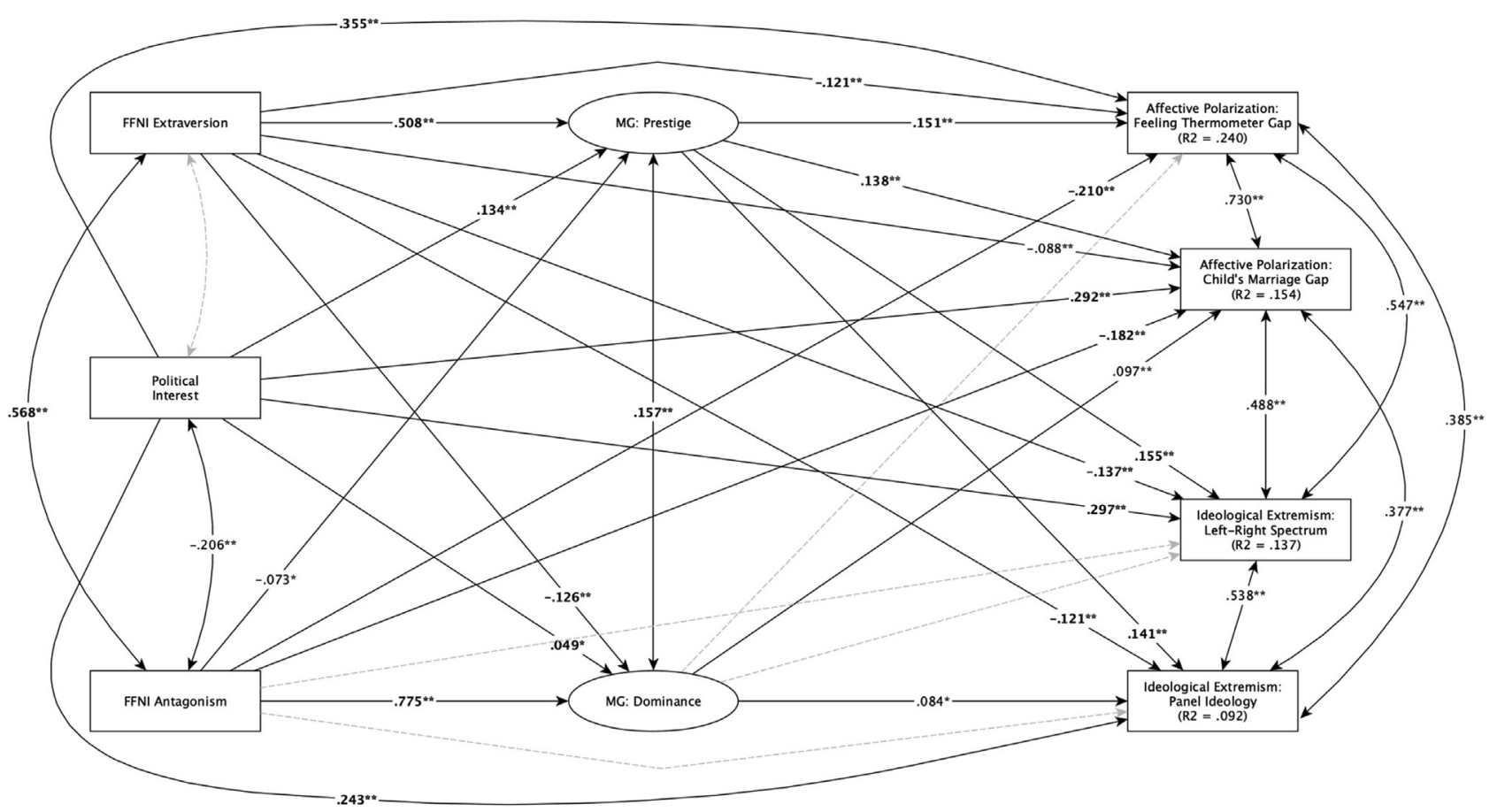

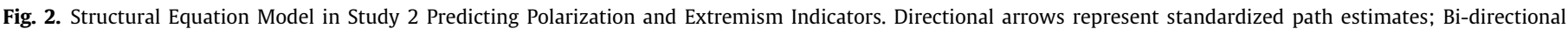

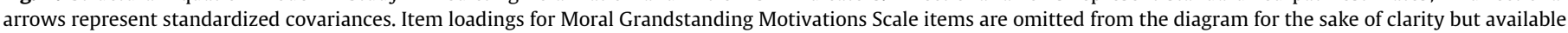

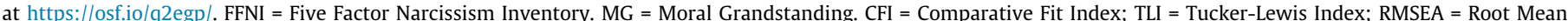
Square Error of Approximation; SRMR $=$ Standardized Root Mean Square Residual. Robust Fit Indices: CFI = 0.977, TLI = 0.966, RMSEA = 0.043, SRMR = 0.038.

Table 3

Study 2: Descriptive Statistics, Internal Consistency Coefficients, and Correlations.

\begin{tabular}{|c|c|c|c|c|c|c|c|c|c|c|c|c|}
\hline & & $\mathrm{M}(\mathrm{SD})$ & $\alpha$ & $\omega$ & 1 & 2 & 3 & 4 & 5 & 6 & 7 & 8 \\
\hline 1. & Moral Grandstanding: Prestige Strivings & $4.86(0.99)$ & 0.767 & 0.770 & & & & & & & & \\
\hline 2. & Moral Grandstanding: Dominance Strivings & $2.33(1.45)$ & 0.908 & 0.909 & $0.163^{* *}$ & & & & & & & \\
\hline 3. & Narc. Antagonism & $2.24(0.70)$ & 0.877 & 0.881 & $0.162^{* *}$ & $0.663^{* *}$ & & & & & & \\
\hline 4. & Narc. Extraversion & $2.92(0.74)$ & 0.741 & 0.744 & $0.407^{* *}$ & $0.303^{* *}$ & $0.568^{* *}$ & & & & & \\
\hline 5. & Ideological Extremism: Panel Ideology & $0.95(0.80)$ & - & - & $0.126^{* *}$ & 0.009 & $-0.079^{* *}$ & $-0.049^{*}$ & & & & \\
\hline 6. & Ideological extremism: Left-Right Spectrum & $\begin{array}{l}56.31 \\
(35.49)\end{array}$ & - & - & $0.132^{* * *}$ & $-0.057^{* * *}$ & $-0.149^{* *}$ & $-0.084^{* *}$ & $0.587^{* *}$ & & & \\
\hline 7. & Political Interest & $3.20(0.09)$ & - & - & $0.154^{* *}$ & $-0.125^{* *}$ & $-0.206^{* *}$ & 0.021 & $0.262^{* *}$ & $0.328^{* *}$ & & \\
\hline 8. & $\begin{array}{l}\text { Affective Polarization: Feeling Thermometer } \\
\text { Gap }\end{array}$ & $\begin{array}{l}44.42 \\
(30.22)\end{array}$ & - & - & $0.121^{* *}$ & $-0.155^{* *}$ & $-0.296^{* *}$ & $-0.150^{* *}$ & $0.456^{* *}$ & $0.619^{* *}$ & $0.415^{* *}$ & \\
\hline 9 & Affective Polarization: Child's Marriage Gap & $\begin{array}{l}34.14 \\
(31.20)\end{array}$ & - & - & $0.128^{* *}$ & $-0.064^{* *}$ & $-0.199^{* *}$ & $-0.091^{* *}$ & $0.445^{* * *}$ & $0.560^{* * *}$ & $0.337^{* *}$ & $0.775^{* *}$ \\
\hline
\end{tabular}

$\alpha=$ Cronbach's Alpha; $\omega=$ McDonald's Omega.

MG = Moral Grandstanding; Narc = Narcissism.

Correlation is significant at the 0.01 level (2-tailed).

We consistently found robust evidence that prestige-motivated aspects of MG were positively related to affective polarization and ideological extremism in all ways in which we measured it. This is consistent with preliminary links between prestige-motivated MG and single-item measures of ideological extremism (Grubbs et al., 2019). That is, prestige-motivated MG was a uniformly positive associate of more extreme political ideology across single-item ideology measures, affective gap measures, and multi-item ideological gap measures. These links persisted even when general political interest and involvement were statistically controlled, and testing of alternative models suggest that our conceptualized pathways (i.e., that polarization and extremism are predicted by prestige-motivated MG) were more consistent with the data than alternative models (i.e., that polarization or extremism predicts prestige-motivated MG).

Though we expected that dominance-motivated aspects of MG would be predictive of affective polarization, we found no support for this notion and some support for its opposite. That is, in Study 1 , we found negative correlations between MG Dominance and ideological extremism. Moreover, in Study 2, raw correlations observed between dominance-motivated MG and affective polarization were reduced to insignificance in latent variable analyses. In our weighted, nationally-representative sample, dominancemotivated MG was not significantly related to any of our measures of affective polarization.

The reasons for the lack of support for our hypotheses regarding dominance-motivated MG are unclear. In all three samples, the raw associations between dominance-motivated MG and narcissistic antagonism were quite large $(r>0.5)$, and the magnitude of these relationships appeared even larger in latent variable analyses. Additionally, across samples, narcissistic antagonism was most often negatively related to polarization and political interest. As such, it is possible that any relationship between dominancemotivated MG and polarization is overshadowed by the negative 
links between narcissistic antagonism and such polarization, and that any residual relationships in structural models are a function of suppression effects. Alternatively, and perhaps more simply, the relationship between prestige-motivated MG and polarization may overshadow any possible connection between dominancemotivated MG and polarization. This would suggest that simple correlations between MG Dominance and affective polarization (as seen in study 2) may be a function of the shared variance between prestige-motivated MG and dominance-motivated MG such that dominance-motivated $\mathrm{MG}$ is unrelated to polarization when controlling for prestige-motivated MG.

\subsection{Implications and future directions}

Links between MG and polarization are not evenly distributed. Although prior empirical work has conceptualized MG as being expressed in terms of prestige strivings (i.e., a desire to be respected, admired, or emulated for one's moral beliefs) and dominance strivings (i.e., a desire to shame or embarrass those that disagree with one's moral beliefs), only the former of these categories is consistently related to affective polarization or more extreme ideological positions. This point is particularly fascinating given the established links between prestige strivings and other politically relevant domains, which we explore below.

Prior works have linked the prestige-motived aspects of MG to many generally positive outcomes. For example, both crosssectionally and over time, prestige-motivated MG is related to greater civic engagement in the form of voting behavior, volunteerism, and philanthropy (Grubbs, Tosi \& Warmke, 2020). Similarly, both cross-sectionally and over time, prestige motivated MG is related to reports of growing closer to others over political and moral issues (Grubbs et al., 2019). In contrast, dominanceoriented aspects of MG are associated with a reduced likelihood of voting and greater reports of conflict and discord over political issues (Grubbs et al., 2019, 2020). Yet, the present results seem to run somewhat counter to these previous works by demonstrating that prestige-motivated MG also seems to be associated with adverse outcomes for civic life. The present work consistently shows that more extreme political views, affective reactions to political views, and partisan ideology are related to prestigemotivated MG.

What follows from these findings is a more nuanced understanding of how MG might be related to public discourse and political polarization more broadly. Specifically, we can consider that prestige-motivated MG might be associated with putatively positive outcomes such as greater civic engagement while also indicating more extreme political views. This is not surprising as more extreme partisans are more politically active (McCarty, 2019). Similarly, although prestige-motivated MG may predict growing closer to others over political issues, such relationship-strengthening does not preclude the possibility of polarization. Prestigemotivated MG may simply be associated with stronger relationships to polarized others (i.e., polarized people bond with others over shared extreme views). In short, prestige-motivated MG may be related to seemingly good things while also facilitating polarization and extremism, which are known to drive a range of negative outcomes at societal levels (McCarty, 2019) and in family relationships (Chen \& Rohla, 2018).

Regarding the weaker relationship between dominancemotivated MG and extremism, we suspect that this is due to inherent differences between dominance and prestige approaches to status seeking. To achieve status, dominance grandstanders are less likely to employ a kind of moral one-upmanship than they are to simply call names or use harsh, condemning language. Crucially, one needs not shift one's moral or political views to assert dominance in this way. Prestige-seeking grandstanders, on the other hand, often attempt to appear more morally impressive or enlightened. These judgments are typically comparative (one is trying to look morally better than others) and contextual (one is using a particular issue or discursive environment to carry out this task). Thus, we hypothesize that attempting to enhance appearances by prestige-MG suggests a more adroit mechanism (i.e., shifting one's moral or political views to a more extreme position) to make oneself morally impressive within a relevant network. In short, we suspect that built into the very nature of prestigestriving is a mechanism for ideological polarization which leads to greater extremism, and that with respect to dominancestriving, this mechanism is either not present, rarely activated, or overridden by some other process more efficient for attaining dominance.

A similar dynamic could be at play concerning affective polarization. One need not take up highly polarized emotions to abuse others via dominance grandstanding. For those motivated by prestige, however, being seen as especially warm toward or approving of one's in-group, and especially cold toward or disapproving of one's out-group, could promote one's status within one's ingroup. Thus, affective polarization also seems more useful as an avenue for seeking prestige than it does for seeking dominance. On the other hand, however, highly polarized emotions would seem to facilitate dominance grandstanding, too. Hatred and resentment of partisan others appear to be natural motivations outlets for status-seeking via dominance behaviors. We admit that the lack of closeness between affective polarization and dominance grandstanding is puzzling in light of the apparent similarities.

The present work also may inform future work related to group polarization more generally as well as intergroup relations. Although the current work focuses on the role that individual differences might play in promoting more extreme ideology and affective reactions to ideological others, the current results also suggest that attempts to seek prestige may also influence intergroup relations. Desires to be seen as inspirational and admirable for one's moral views (i.e., prestige-motivated grandstanding) consistently predicted not only more extreme ideological positions but also more extreme affective responses to others. Accordingly, it seems that status seeking via prestige within one's own group might ultimately predict more volatile and negative evaluations of members of the outgroup.

\section{Limitations}

The primary limitations of the present work are obvious. We relied exclusively on self-report data using cross-sectional samples in a purely U.S. context. As such, we urge caution before interpreting the present findings as being representative of anything more than associations between related domains in the American cultural context. Although our sampling methods were rigorous and representative, future longitudinal work is needed to determine if prestige-motivated aspects of MG are causing polarization or driving some parts of polarization. Given the cross-sectional nature of our work, we acknowledge that another plausible interpretation of our data is that various aspects of polarization are driving prestige-motivated MG. However, given our tests of such alternative models, we contend that this is less likely than our proposed model positing that prestige-motivated MG leads to polarization.

We also note that ideological extremism is likely to occur with respect to specific issues, such as the morality of abortion, minimum wage laws, immigration, or tax rates. Although we evaluated ideological extremism within the context of specific domains in Study 1 (e.g., fiscal policy), we did not examine specific issues themselves (e.g., tax law). MG may lead individuals to take up increasingly extreme views or attitudes on specific issues, particularly those that are deemed especially important to one's social 
group. Thus, we would expect MG to be associated with the adoption of more extreme views on issues that are likely to confer social status within one's network. This presents a need for both longitudinal research examining MG and polarization broadly and future work examining how MG might lead to extremism along specific moral and political issues over time.

Finally, we note that a number of potentially important covariates were not included in our study. For example, we did not assess general political knowledge, which could impact our findings as prior works have shown that political knowledge is often associated with greater ideological extremism (Bakker, Lelkes, \& Malka, 2020; Drummond \& Fischhoff, 2017; Guay \& Johnston, 2020; Zaller, 1992). Similarly, we did not assess general belief superiority (i.e., the notion that one has better beliefs or ideas than others). This may be particularly relevant given literature suggesting ideological extremism is indeed related to belief superiority (Toner et al., 2013) and prestige motivated MG is characterized by a desire to be seen as special or admirable for one's beliefs.

\section{Conclusions}

Across three samples, involving undergraduate students and nationally-representative U.S. cross-sections, we found consistent support for the notion that that moral grandstanding is linked to ideological extremism and affective polarization. These findings are particularly clear for prestige-motivated grandstanding, and less so for dominance motivated grandstanding. Collectively, our findings point to the importance of considering status seeking as an associate of polarization-both ideological and affective--and indicate a need for future research examining whether status seeking predicts increases in polarization over time or in specific issue domains.

\section{Declaration of Competing Interest}

The authors declare that they have no known competing financial interests or personal relationships that could have appeared to influence the work reported in this paper.

\section{Acknowledgements}

We gratefully acknowledge the support of the Charles Koch Foundation, the National Institute of Civil Discourse, and Bowling Green State University in funding this research.

\section{References}

Abramowitz, A. I., \& Saunders, K. L. (2008). Is polarization a myth?. The Journal of Politics, 70(2), 542-555. https://doi.org/10.1017/S0022381608080493.

Anderson, C., Hildreth, J. A. D., \& Howland, L. (2015). Is the desire for status a fundamental human motive? A review of the empirical literature. Psychological Bulletin, 141(3), 574-601. https://doi.org/10.1037/a0038781.

Bakker, B. N., Lelkes, Y., \& Malka, A. (2020). Understanding partisan cue receptivity: Tests of predictions from the bounded rationality and expressive utility perspectives. The Journal of Politics, 82(3), 1061-1077. https://doi.org/10.1086/ 707616.

Banda, K. K., \& Cluverius, J. (2018). Elite polarization, party extremity, and affective polarization. Electoral Studies, 56, 90-101. https://doi.org/10.1016/ j.electstud.2018.09.009.

Blatz, C. W., \& Mercier, B. (2018). False polarization and false moderation: Political opponents overestimate the extremity of each other's ideologies but underestimate each other's certainty. Social Psychological and Personality Science, 9(5), 521-529. https://doi.org/10.1177/1948550617712034.

Brady, W. J., \& Crockett, M. J. (2019). How effective is online outrage?. Trends in Cognitive Sciences, 23(2), 79-80. https://doi.org/10.1016/j.tics.2018.11.004.

Brady, W. J., Crockett, M., \& Van Bavel, J. J. (2019). The MAD model of moral contagion: The role of motivation, attention and design in the spread of moralized content online [Preprint]. PsyArXiv. https://doi.org/10.31234/osf.io/ pz9g6.

Brandt, M. J., Evans, A. M., \& Crawford, J. T. (2015). The unthinking or confident extremist? Political extremists are more likely than moderates to reject experimenter-generated anchors. Psychological Science, 26(2), 189-202. https://doi.org/10.1177/0956797614559730.

Brandt, M. J., Reyna, C., Chambers, J. R., Crawford, J. T., \& Wetherell, G. (2014). The ideological-conflict hypothesis: Intolerance among both liberals and conservatives. Current Directions in Psychological Science, 23(1), 27-34. https:// doi.org/10.1177/0963721413510932.

Brewer, M. B. (2011). Optimal distinctiveness theory: Its history and development. P. AM Van Lange, A. Kruglanski, \& ET Higgins, Handbook of Theories of Social Psychology, 2, 81-98.

Chen, M. K., \& Rohla, R. (2018). The effect of partisanship and political advertising on close family ties. Science, 360(6392), 1020-1024. https://doi.org/ $10.1126 /$ science.aag1433.

Cheng, J. T., Tracy, J. L., Foulsham, T., Kingstone, A., \& Henrich, J. (2013). Two ways to the top: Evidence that dominance and prestige are distinct yet viable avenues to social rank and influence. Journal of Personality and Social Psychology, 104(1), 103-125. https://doi.org/10.1037/a0030398.

Crockett, M. J. (2017). Moral outrage in the digital age. Nature Human Behaviour, 1 (11), 769. https://doi.org/10.1038/s41562-017-0213-3.

Dimock, M., Doherty, C., Kiley, J., \& Oates, R. (2014). Political Polarization in the American Public (p. 124).

Divided States of America (2017). In Frontline. Public Broadcasting Corporation.

Doherty, C., Kiley, J., Tyson, A., \& Johnson, B. (2019). Public Highly Critical of State of Political Discourse in the U.S. (p. 104).

Druckman, J. N., \& Levendusky, M. S. (2019). What do we measure when we measure affective polarization?. Public Opinion Quarterly, 83(1), 114-122. https://doi.org/10.1093/poq/nfz003.

Drummond, C., \& Fischhoff, B. (2017). Individuals with greater science literacy and education have more polarized beliefs on controversial science topics. In Proceedings of the National Academy of Sciences. https://doi.org/10.1073/ pnas.1704882114.

Fernbach, P. M., Rogers, T., Fox, C. R., \& Sloman, S. A. (2013). Political extremism is supported by an illusion of understanding. Psychological Science, 24(6), 939-946. https://doi.org/10.1177/0956797612464058.

Fiorina, M. P., \& Abrams, S. J. (2008). Political polarization in the American public. Annual Review of Political Science, 11(1), 563-588. https://doi.org/10.1146/ annurev.polisci.11.053106.153836.

Funder, D. C., \& Ozer, D. J. (2019). Evaluating effect size in psychological research: Sense and nonsense. Advances in Methods and Practices in Psychological Science, 251524591984720. https://doi.org/10.1177/2515245919847202.

Garrett, K. N., \& Bankert, A. (2018). The moral roots of partisan division: How moral conviction heightens affective polarization. British Journal of Political Science, 1-20. https://doi.org/10.1017/S000712341700059X.

Garrett, R. K., Long, J. A., \& Jeong, M. S. (2019). New evidence on group polarization from partisan media to misperception: Affective polarization as mediator. Journal of Communication, 69(5), 490-517. https://doi.org/10.1093/joc/jqz028.

Grubbs, J. B., Warmke, B., Tosi, J., James, A. S., \& Campbell, W. K. (2019). Moral grandstanding in public discourse: Status-seeking motives as a potential explanatory mechanism in predicting conflict. PLOS ONE, 14(10), e0223749. https://doi.org/10.1371/journal.pone.0223749.

Grubbs, Tosi, and Warmke (2020) Moral Grandstanding and Civic Engagement: An Exploratory Consideration. Manuscript under publication review.

Guay, B., \& Johnston, C. D. (2020). Ideological asymmetries and the determinants of politically motivated reasoning. /publication/ja_2020_pmr_ajps/.

Hewstone, M., Rubin, M., \& Willis, H.(2002). Intergroup bias. Annual Review of Psychology, 53(1), 575-604. https://doi.org/10.1146/annurev.psych.53.100901.135109.

Iyengar, S., Lelkes, Y., Levendusky, M., Malhotra, N., \& Westwood, S. J. (2019). The origins and consequences of affective polarization in the United States. Annual Review of Political Science, 22(1), annurev-polisci-051117-073034. https://doi. org/10.1146/annurev-polisci-051117-073034.

Iyengar, S., Sood, G., \& Lelkes, Y. (2012). Affect not ideology. Public Opinion Quarterly, 76(3), 405-431. https://doi.org/10.1093/poq/nfs038.

Iyengar, S., \& Westwood, S. J. (2015). Fear and loathing across party lines: New evidence on group polarization. American Journal of Political Science, 59(3), 690-707. https://doi.org/10.1111/ajps.12152.

Johnston, C. D. (2018). Authoritarianism, affective polarization, and economic ideology Political Psychology, 39(S1), 219-238. https://doi.org/10.1111/pops.12483.

Lammers, J., Koch, A., Conway, P., \& Brandt, M. J. (2017). The political domain appears simpler to the politically extreme than to political moderates. Social Psychological and Personality Science, 8(6), 612-622. https://doi.org/10.1177/ 1948550616678456.

Lelkes, Y. (2016). Mass polarization: Manifestations and measurements. Public Opinion Quarterly, 80(S1), 392-410. https://doi.org/10.1093/poq/nfw005.

Leonardelli, G. J., Pickett, C. L., \& Brewer, M. B. (2010). Optimal distinctiveness theory: A framework for social identity, social cognition, and intergroup relations. Advances in experimental social psychology (Vol. 43, pp. 63-113). Elsevier.

Litman, L., Robinson, J., \& Abberbock, T. (2017). TurkPrime.com: A versatile crowdsourcing data acquisition platform for the behavioral sciences. Behavior Research Methods, 49(2), 433-442. https://doi.org/10.3758/s13428-016-0727-z.

Loch, C., Yaziji, M., \& Langen, C. (2001). The fight for the alpha position: Channeling status competition in organizations. European Management Journal, 19(1), 16-25. https://doi.org/10.1016/S0263-2373(00)00067-0.

Mackie, D., \& Cooper, J. (1984). Attitude polarization: Effects of group membership. Journal of Personality and Social Psychology, 46(3), 575.

Mackie, D. M. (1986). Social identification effects in group polarization. Journal of Personality and Social Psychology, 50(4), 720. 
Mackie, D. M., Maitner, A. T., \& Smith, E. R. (2016). Intergroup emotions theory. In Handbook of prejudice, stereotyping, and discrimination, pp. 149-174). Psychology Press.

Martin, G. J., \& Yurukoglu, A. (2017). Bias in cable news: Persuasion and polarization. American Economic Review, 107(9), 2565-2599. https://doi.org/ 10.1257/aer.20160812.

Mason, L. (2015). “I Disrespectfully Agree”: The differential effects of partisan sorting on social and issue polarization. American Journal of Political Science, 59 (1), 128-145. https://doi.org/10.1111/ajps.12089.

McCarty, N. (2019). Polarization: What everyone needs to know ${ }^{\circledR}$. Oxford University Press.

Moscovici, S., \& Zavalloni, M. (1969). The group as a polarizer of attitudes. Journal of Personality and Social Psychology, 12(2), 125-135. https://doi.org/10.1037/ h0027568.

Neel, R., Kenrick, D. T., White, A. E., \& Neuberg, S. L. (2015). Individual differences in fundamental social motives. Journal of Personality and Social Psychology, 110(6), 887. https://doi.org/10.1037/pspp0000068.

Nesi, J., \& Prinstein, M. J. (2019). In search of likes: Longitudinal associations between adolescents' digital status seeking and health-risk behaviors. Journal of Clinical Child \& Adolescent Psychology, 48(5), 740-748. https://doi.org/10.1080/ 15374416.2018.1437733.

R Core Team (2018). R: A language and environment for statistical computing. R Foundation for Statistical Computing. https://www.R-project.org/.

Riek, B. M., Mania, E. W., \& Gaertner, S. L. (2006). Intergroup threat and outgroup attitudes: A meta-analytic review. Personality and Social Psychology Review, 10 (4), 336-353. https://doi.org/10.1207/s15327957pspr1004 4.

Rivers, D. (2016). Pew research: YouGov consistently outperforms competitors on accuracy | YouGov. https://today.yougov.com/topics/finance/articles-reports/ 2016/05/13/pew-research-yougov.

Robbins, J. M., \& Krueger, J. I. (2005). Social projection to ingroups and outgroups: A review and meta-analysis. Personality and Social Psychology Review, 9(1), 32-47. https://doi.org/10.1207/s15327957pspr0901_3.

Rosseel, Y. (2012). lavaan: An R package for structural equation modeling and more Version 0.5-12 (BETA). Journal of Statistical Software, 42, 1-36.
Sherman, E. D., Miller, J. D., Few, L. R., Campbell, W. K., Widiger, T. A., Crego, C., \& Lynam, D. R. (2015). Development of a short form of the five-factor narcissism inventory: The FFNI-SF. Psychological Assessment, 27(3), 1110-1116. https://doi. org/10.1037/pas0000100.

Smith, E. R., Seger, C. R., \& Mackie, D. M. (2007). Can emotions be truly group level? Evidence regarding four conceptual criteria. Journal of Personality and Social Psychology, 93(3), 431-446. https://doi.org/10.1037/0022-3514.93.3.431.

Toner, K., Leary, M. R., Asher, M. W., \& Jongman-Sereno, K. P. (2013). Feeling superior is a bipartisan issue: Extremity (not direction) of political views predicts perceived belief superiority. Psychological Science, 24(12), 2454-2462. https://doi.org/10.1177/0956797613494848.

Tosi, J., \& Warmke, B. (2016). Moral grandstanding. Philosophy E' Public Affairs, 44(3), 197-217. https://doi.org/10.1111/papa.12075.

Tosi, J., \& Warmke, B. (2020). Grandstanding: The use and abuse of moral talk. Oxford University Press.

van Prooijen, J.-W., \& Krouwel, A. P. M. (2019). Psychological features of extreme political ideologies. Current Directions in Psychological Science, 28(2), 159-163. https://doi.org/10.1177/0963721418817755.

van Prooijen, J.-W., Krouwel, A. P. M., \& Emmer, J. (2018). Ideological responses to the EU refugee crisis: The left, the right, and the extremes. Social Psychological and Personality Science, 9(2), 143-150. https://doi.org/10.1177/1948550617731501.

Walasek, L., \& Brown, G. D. A. (2015). Income inequality and status seeking: Searching for positional goods in unequal U.S. States. Psychological Science, 26 (4), 527-533. https://doi.org/10.1177/0956797614567511.

Wegener, D. T., Downing, J., Krosnick, J. A., \& Petty, R. E. (1995). Measures and manipulations of strength-related properties of attitudes: Current practice and future directions. In Attitude strength: Antecedents and consequences (pp. 455-487). Lawrence Erlbaum Associates Inc..

Westfall, J., Van Boven, L., Chambers, J. R., \& Judd, C. M. (2015). Perceiving political polarization in the United States: Party identity strength and attitude extremity exacerbate the perceived partisan divide. Perspectives on Psychological Science, 10(2), 145-158. https://doi.org/10.1177/1745691615569849.

Zaller, J. R. (1992). The nature and origins of mass opinion. Cambridge University Press. 